\title{
Competências Relevantes a Profissionais da Área de T\&D de uma Organização Pública do Distrito Federal
}

\author{
Maria de Fátima Bruno-Faria \\ Hugo Pena Brandão
}

\section{Resumo}

A presente pesquisa teve como objetivo principal elaborar um instrumento destinado a identificar competências profissionais relevantes a profissionais de T\&D de uma organização pública do Distrito Federal, e, por conseqüência, evidenciar as necessidades de desenvolvimento de competências em seus diferentes segmentos. Para tanto, foram realizadas pesquisas quantitativas (survey) e qualitativas (análise de documentos, entrevistas e técnicas de brainstorming e brainwriting). Para a construção do questionário, que em sua versão final ficou com 86 itens, foram realizadas análises semântica e de juízes. Os dados foram coletados por aplicação coletiva do instrumento, sendo a amostra constituída por 66 servidores da organização. Os resultados revelaram que, em média, as competências profissionais descritas no questionário foram consideradas muito importantes para o bom desempenho dos referidos servidores. Além disso, foram identificadas algumas competências que necessitam ser desenvolvidas pela implementação de ações de aprendizagem.

Palavras-chaves: gestão de pessoas na administração pública; gestão de competências; identificação de necessidades de aprendizagem.

\begin{abstract}
The main objective of this study has been to develop a device for identifying relevant professional competencies for T\&D employees of a Brazilian public organization aiming to evidence the competency lacking in different segments of the organization. Data were collected through quantitative surveys and qualitative means (document analysis, interviews and techniques of brainstorming and brainwriting). In order to model the 86-item questionnaire, semantic and experts analysis were conducted. The questionnaires were submited to a sample of 66 employees of the organization. The results showed that, in average, the competencies listed in the questionnaire were considered very important for the employees' professional performance. In addition, several competency gaps were identified, which need to be treated by implementing training actions.
\end{abstract}

Key words: human resources management; competency-based management; learning needs. 


\section{INTRODUÇÃO}

A gestão baseada em competências - ou simplesmente gestão de competências - tem sido apontada como uma tecnologia alternativa dos modelos tradicionalmente utilizados pelas organizações (Brandão e Guimarães, 2001; Santos, 2001). Baseando-se no pressuposto de que o domínio de certos recursos é determinante do desempenho superior de uma organização, a gestão de competências propõese a integrar e orientar esforços, sobretudo os relacionados à gestão de pessoas, visando a desenvolver e sustentar competências consideradas fundamentais à consecução de objetivos organizacionais (Prahalad e Hamel, 1990; Durand, 1998).

No fim da Idade Média, a expressão competência pertencia essencialmente à linguagem jurídica. Dizia respeito à faculdade atribuída a uma pessoa ou a uma corte para apreciar e julgar certas questões. Por extensão, o termo veio a designar o reconhecimento social sobre a capacidade de alguém pronunciar-se a respeito de assunto específico. Mais tarde, passou a ser utilizado para qualificar o indivíduo capaz de realizar determinado trabalho (Isambert-Jamati, 1997).

No início do século passado, com o advento da Administração Científica, as empresas procuravam aperfeiçoar em seus empregados as habilidades necessárias ao exercício de certas funções, enfocando aspectos operacionais do trabalho e especificações do cargo. Sob esta perspectiva, referiam-se à competência como um conjunto de conhecimentos e habilidades que credenciavam uma pessoa a exercer certa função. Mais tarde, em razão de pressões sociais e do aumento da complexidade das relações de trabalho, as organizações passaram a considerar, no processo de desenvolvimento de seus empregados, não só conhecimentos e habilidades, mas também aspectos sociais e atitudinais. Reconheceu-se que as pessoas não são competentes apenas do ponto de vista cognitivo, mas também no que se refere aos aspectos emocionais (Santos, 2001).

Algumas concepções, então, passaram a contemplar a valorização das atitudes como recurso determinante da competência. Zarifian (1996), por exemplo, ao definir competência, faz alusão à metacognição e a atitudes relacionadas ao trabalho, baseando-se na premissa de que, em ambiente dinâmico e competitivo, não é possível considerar o trabalho como um conjunto de tarefas ou atividades predefinidas e estáticas. Para esse autor, competência significa "assumir responsabilidades frente a situações de trabalho complexas [aliado] ao exercício sistemático de uma reflexividade no trabalho" (Zarifian, 1996, p. 5), que permita ao profissional lidar com eventos inéditos, surpreendentes e de natureza singular. 
A freqüente utilização do termo competência no campo da gestão organizacional fez com que ele adquirisse variadas conotações, sendo, não raras vezes, utilizado de diferentes maneiras, conforme relatam McLagan (1997), Brandão e Guimarães (2001) e Ruas (2001). Abordagens mais respeitadas, contudo, buscam não só considerar diversas dimensões do trabalho, mas também associar a competência ao desempenho, conforme sugerem Boyatzis (1982), Spencer e Spencer (1993) e Ruas (2001). Nessa mesma linha, Ropé e Tanguy (1997) afirmam que um dos aspectos essenciais da competência é que ela não pode ser compreendida de forma separada da ação. Dutra, Hipólito e Silva (1998), por sua vez, definem competência como a capacidade de uma pessoa gerar resultados dentro dos objetivos organizacionais.

Sob esta perspectiva, que parece ter aceitação mais ampla tanto no meio acadêmico como no ambiente empresarial, competências representam combinações sinérgicas de conhecimentos, habilidades e atitudes, expressas pelo desempenho profissional, dentro de determinado contexto organizacional (Durand, 2000; Nisembaum, 2000). As competências são reveladas, então, quando as pessoas agem em face das situações profissionais com as quais se defrontam (Zarifian, 1999). Servem como nexo entre as condutas individuais e a estratégia da organização (Prahalad e Hamel, 1990).

As competências são descritas por alguns autores, utilizando-se pautas ou referenciais de desempenho (Nisembaum, 2000; Santos, 2001), de forma que o profissional demonstraria deter dada competência por meio da adoção de certos comportamentos observáveis no ambiente de trabalho. Outros (Brandão, 1999; Bruno-Faria e Brandão, 2002), por opção metodológica, procuram descrever também os recursos ou dimensões da competência, ou seja, os conhecimentos, habilidades e atitudes que se pressupõem necessários para que a pessoa possa apresentar o desempenho desejado.

Conhecimentos, habilidades e atitudes representam, então, recursos ou dimensões interdependentes da competência (Durand, 1998). O conhecimento diz respeito a um conjunto de informações armazenadas na memória da pessoa, que têm relevância e causam impacto em seu comportamento. Habilidade referese à capacidade de fazer uso produtivo do conhecimento, ou seja, ao saber como fazer algo. $E$ a atitude, por sua vez, diz respeito à predisposição da pessoa em relação ao trabalho, a objetos ou a situações (Brandão, 1999).

Até aqui, referiu-se a competência no plano individual, como um atributo relacionado a uma pessoa. Alguns autores, no entanto, elevam o conceito a equipes de trabalho ou mesmo à organização como um todo. Zarifian (1999), por exemplo, sustenta que em cada grupo de trabalho se manifesta uma competência coletiva, que representa mais do que a simples soma das competências de seus membros. 
Isso porque há uma sinergia entre as competências individuais e as interações sociais existentes no grupo. Le Boterf (1999) reforça esse entendimento, ressaltando que as competências coletivas emergem das cooperações, trocas e articulações estabelecidas entre as competências individuais dos componentes da equipe.

Prahalad e Hamel (1990), por sua vez, tratam do conceito no nível organizacional, referindo-se à competência como atributo da organização, que lhe permite atingir seus objetivos estratégicos, conferindo competitividade e gerando benefícios percebidos pelos clientes. O design de motores eficientes da Honda, a ótica de alta precisão da Canon, e a capacidade de miniatuarização da Sony são exemplos de competência citados por esses autores. É possível, então, classificar as competências como profissionais ou humanas (aquelas relacionadas a indivíduos ou a equipes de trabalho) e organizacionais (aquelas inerentes à organização como um todo), ressaltando-se que as competências profissionais, aliadas a outros recursos, dão origem e sustentação às competências organizacionais.

A partir desses pressupostos teóricos, torna-se possível entender a gestão de competências como modelo de gestão organizacional. Guimarães et al. (2001) sugerem o diagrama disposto na Figura 1, a seguir, para ilustrar as etapas desse modelo. Trata-se de processo contínuo que toma como referência a estratégia corporativa para orientar esforços em torno da captação e/ou do desenvolvimento das competências necessárias à consecução de objetivos organizacionais.

\section{Figura 1: Modelo de Gestão Organizacional Baseada nas Competências}

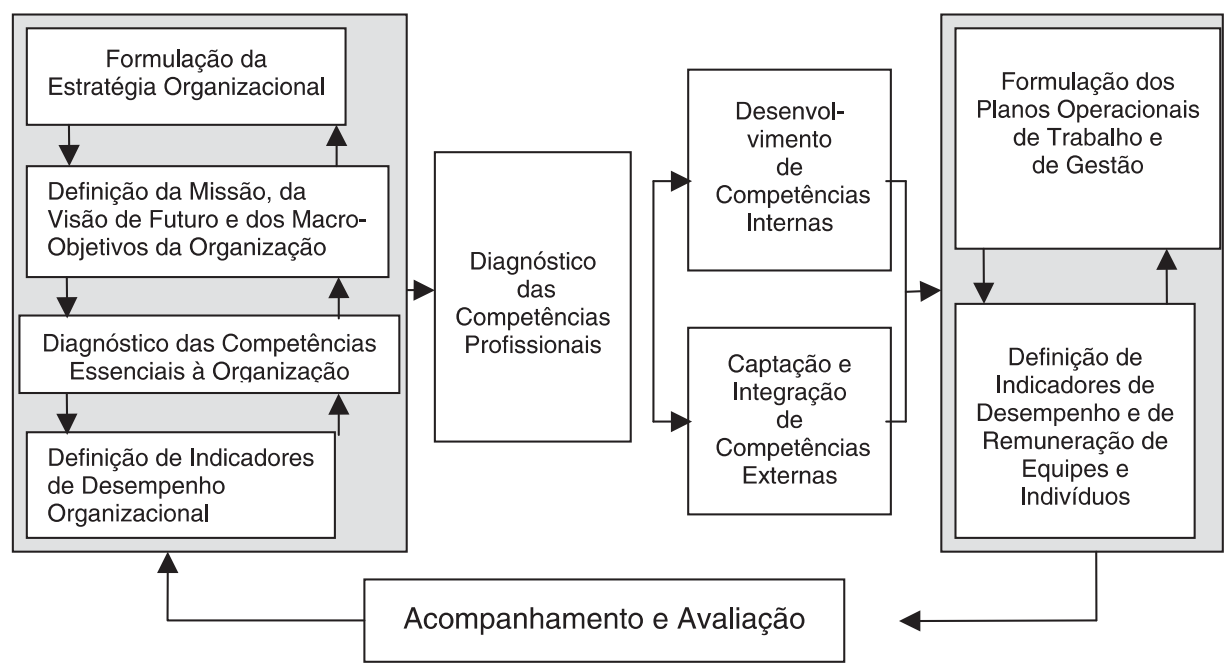

Fonte: adaptado de Guimarães et al. (2001, p. 4). 
Nesse modelo há um momento inicial de formulação da estratégia da organização, quando se definem sua missão, sua visão de futuro e seus objetivos estratégicos. Missão é o propósito principal ou a razão pela qual uma organização existe. Visão diz respeito ao estado futuro desejado pela organização, ou seja, aquilo que se deseja ser em futuro próximo. Os objetivos estratégicos, por sua vez, representam alvos a atingir ou a situação a ser buscada pela organização em dado período de tempo (Souza, 2001).

Em seguida, a organização identificaria as competências organizacionais necessárias à consecução de seus objetivos. Definiria também indicadores de desempenho no nível corporativo, os quais representariam medidas da eficiência ou da eficácia das ações adotadas para concretizar a visão de futuro. Seria possível, assim, realizar um diagnóstico das competências profissionais, ou seja, identificar o gap - ou lacuna - existente entre as competências necessárias à consecução dos objetivos estratégicos e as competências internas disponíveis na organização, conforme ilustra a Figura 2.

\section{Figura 2: Identificação do Gap (Lacuna) de Competências}

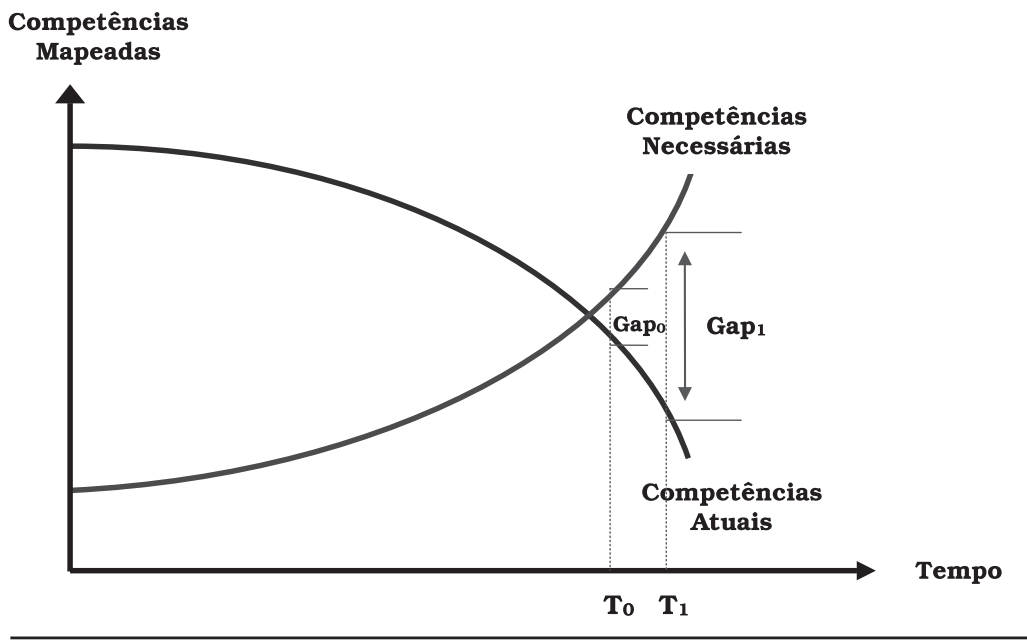

Fonte: adaptado de Ienaga (1998, p. 13).

Esse diagnóstico, por sua vez, subsidia decisões de investimento no desenvolvimento e/ou na captação de competências. A captação diz respeito à seleção de competências externas e sua integração ao ambiente organizacional, que pode se dar, no nível individual, por intermédio de ações de recrutamento e seleção de pessoas e, no nível organizacional, por meio de joint-ventures ou alianças estratégicas. O desenvolvimento refere-se ao aprimoramento das competências internas disponíveis na organização, podendo dar-se, no nível 
individual, mediante treinamento e, no nível organizacional, por intermédio de investimentos em pesquisa. Para Stewart (1998, p. 84), com a gestão de competências "a idéia é que [a organização e seus profissionais] eliminem as lacunas entre o que podem fazer e o que os clientes esperam que eles façam”.

Essas etapas permitiriam a formulação de planos operacionais e de gestão e dos respectivos indicadores de desempenho e de remuneração de equipes e indivíduos. Por fim, há uma etapa de acompanhamento e avaliação que funciona como mecanismo de retroalimentação ou feedback dentro de uma abordagem sistêmica, à medida que os resultados alcançados são comparados com aqueles que eram esperados.

Vale ressaltar ainda que para identificar a lacuna de competências, alguns autores propõem a utilização de sistemas de gestão do desempenho (Brandão e Guimarães, 2001). Isto porque, se o desempenho no trabalho expressa competências de pessoas, grupos e organizações, eventual deficiência no desempenho é indicativa da existência de uma lacuna de competências. Outros autores sugerem a utilização de instrumentos de auto e hetero-avaliação, por meio dos quais empregados e seus superiores hierárquicos manifestam sua percepção sobre o grau de domínio que os primeiros possuem em relação a determinadas competências, indicando, assim, suas prioridades de desenvolvimento profissional.

Um instrumento desenvolvido por Magalhães (1996), por exemplo, possui como itens os conhecimentos, habilidades e atitudes que se pressupõem componentes de determinadas competências profissionais. A idéia é solicitar aos respondentes que avaliem o grau de importância de cada item do questionário, bem como o domínio que eles possuem em relação aos conhecimentos, habilidades e atitudes constantes do instrumento. Assim, quanto maior a importância e menor o domínio sobre o item, maior a lacuna (gap) de competências e, por conseguinte, a necessidade de o respondente capacitar-se.

São relatados, a seguir, as características da organização estudada, as justificativas e objetivos desta pesquisa, bem como os procedimentos utilizados na coleta e análise de dados.

\section{Metodologia}

O presente estudo teve por finalidade construir um instrumento destinado a identificar competências profissionais relevantes a funcionários que atuam na área de T\&D em uma organização pública do Distrito Federal. Com a aplicação do instrumento, pretendeu-se realizar um diagnóstico das lacunas de competências 
dos profissionais de T\&D da Organização, de forma a subsidiar a elaboração de um plano de desenvolvimento profissional para esses servidores, nas diferentes funções que nela ocupam.

Para tanto, foram realizadas pesquisas quantitativas (survey) e qualitativas (análise de documentos, entrevistas e técnicas de brainstorming e brainwriting), conforme descrito adiante.

\section{Características da Organização Estudada}

A organização investigada tem como principal atividade a promoção de ações de T\&D destinadas a servidores públicos dos níveis estratégico, tático e operacional. A Organização passou por processo de reestruturação nos últimos anos - deixou de responder por outras funções de gestão de pessoas e passou a dedicar-se exclusivamente às ações de $T \& D$ - e, por consequiência, percebeuse a necessidade de identificação das competências a serem desenvolvidas por seus servidores, a fim de que apresentassem desempenhos compatíveis com o esperado em suas novas funções.

\section{Embasamento Teórico para Construção do Instrumento de Pesquisa}

O objetivo principal do instrumento é possibilitar a identificação dos graus de importância - para a consecução de objetivos organizacionais - atribuídos pelos funcionários da Organização aos conhecimentos, habilidades e atitudes descritos no questionário, assim como verificar a lacuna existente entre esses graus de importância e o domínio dos funcionários sobre tais conhecimentos, habilidades e atitudes.

Tendo em vista a necessidade de participação de um grupo de servidores da Organização no processo de pesquisa, considerou-se necessário criar espaço para discussão teórica do tema, a fim de tornar mais produtiva a ação dos envolvidos na atividade. Portanto foi realizada uma palestra sobre gestão de competências, aberta a todos os servidores da Organização, tendo a participação de 88 servidores. Além disso, foi realizado um seminário sobre o tema para 30 profissionais da Organização e do órgão público ao qual ela se vinculava hierarquicamente, do qual participaram aqueles que fariam parte do grupo de pesquisa. A palestra e o seminário foram ministrados por um dos autores do presente estudo.

O grupo de pesquisa foi constituído pela primeira autora deste artigo e por oito servidores da Organização. Tais servidores tinham experiência em T\&D, curso 
superior completo, mas pouca vivência na condução de pesquisas, tendo sido necessário, portanto, treiná-los sobre aspectos teóricos relacionados à gestão de competências, sobre pesquisa qualitativa e quantitativa, construção de questionários e realização de entrevistas.

\section{Identificação das Competências Organizacionais}

Tendo em vista a subordinação da Organização à outra unidade, que neste estudo será denominada Unidade Principal, procurou-se mapear as competências organizacionais necessárias à consecução dos objetivos institucionais da Unidade Principal e da Organização, como primeira etapa do processo de identificação dos conhecimentos, habilidades e atitudes relevantes para os profissionais de T\&D.

Para isso, o grupo realizou pesquisas documentais, a partir da análise do Plano Estratégico da Unidade Principal, bem como de portarias e decretos governamentais. Foram feitas dez entrevistas, com a participação de diretores, chefes de gabinete, subsecretários e assessores dos dois órgãos. Na ocasião, foi apresentado aos entrevistados o conceito de competência organizacional ${ }^{(1)}$, solicitando-se-lhes "relacionar algumas competências organizacionais necessárias à concretização do Plano Estratégico” da Unidade Principal.

Chegou-se às seguintes competências organizacionais necessárias à Unidade Principal: valorização do servidor público; excelência na prestação de serviços; gestão moderna, ágil e eficaz; e normatização e integração das ações administrativas.

Com base nesse levantamento e com o auxílio de três diretoras e de três assessoras da Organização, identificaram-se, também, as competências relevantes a Organização (competências necessárias ao cumprimento do seu papel institucional), quais sejam: identificação de necessidades de desenvolvimento profissional dos servidores públicos; estímulo ao autodesenvolvimento e à profissionalização dos servidores públicos; e desenvolvimento de competências profissionais dos servidores públicos.

\section{Competências Profissionais Relevantes aos Funcionários da Organização}

Com base nas competências da Organização, deu-se início ao processo de identificação dos conhecimentos, habilidades e atitudes relevantes aos seus profissionais. Com tal objetivo, foram feitos levantamentos diversificados junto aos diferentes segmentos envolvidos nas atividades da Organização. Na Figura 3 encontram-se sintetizadas as técnicas de pesquisas utilizadas nessa etapa. 


\section{Figura 3: Participantes da Pesquisa e Técnicas Utilizadas para Coleta de Dados}

\begin{tabular}{|l|l|}
\hline \multicolumn{1}{|c|}{ Técnica de Pesquisa } & \multicolumn{1}{c|}{ Participantes } \\
\hline Brainstorming & $\begin{array}{l}\text { Duas turmas que participavam de treinamento } \\
\text { na ocasião da pesquisa na Organização } \\
\text { Servidores da Organização }\end{array}$ \\
\hline $\begin{array}{l}\text { Questionário, via correio } \\
\text { eletrônico }\end{array}$ & Sete instrutores da Organização \\
\hline Brainwriting & $\begin{array}{l}\text { Três diretoras, três assessores e sete } \\
\text { servidores da Organização } \\
\text { Membros do grupo de pesquisa }\end{array}$ \\
\hline
\end{tabular}

Em todos os casos relacionados na Figura 3, foram apresentadas aos participantes as competências da Organização e formulou-se-lhes a seguinte pergunta: "O que você considera que os servidores desta Organização devem conhecer, saber fazer e ter iniciativa para fazer, de modo que a Organização tenha êxito em suas ações?”

\section{Construção dos Itens do Instrumento}

Com base nos levantamentos realizados, foram elaborados 102 itens que representam componentes de competências profissionais relevantes aos funcionários da Organização. Tais itens foram categorizados em conhecimentos, habilidades e atitudes.

Para elaboração dos itens, procurou-se expressar apenas uma única idéia em cada questão, de forma clara, objetiva e isenta de ambigüidades e duplicidades. Foram analisados ainda outros instrumentos de pesquisa desenvolvidos com base científica para propósitos semelhantes aos do presente estudo.

\section{Análise Teórica dos Itens}

A fim de se verificar o grau de compreensão dos itens por parte do grupo de profissionais a que se destinava o instrumento, realizou-se análise semântica. Optou-se, inicialmente, por utilizar quatro grupos distintos de servidores da Organização, dois com ensino médio completo e dois com formação superior, pois se constituíam nos níveis de escolaridade da quase totalidade dos profissionais da Organização.

Solicitou-se aos participantes que criticassem os itens do instrumento, as escalas de respostas, as três questões abertas e os itens referentes aos dados pessoais e profissionais que compunham o questionário. Poucos itens apresentaram algum 
grau de dificuldade de compreensão e, à medida que eram reformulados, com base na crítica dos participantes e mantendo-se a idéia que se desejava expressar, passavam a ser mais bem compreendidos, tendo sido concluída tal análise.

Com a finalidade de verificar a pertinência dos itens aos atributos que pretendiam medir (Pasquali, 1997), o instrumento foi submetido à análise de juízes (cinco especialistas no tema competências profissionais). Todos tinham como formação mestrado em Administração ou em Psicologia Social e do Trabalho e já haviam participado de análises semelhantes. Os questionários foram enviados via correio eletrônico, solicitando-se aos especialistas que classificassem os itens em conhecimentos, habilidades e atitudes, e criticassem as instruções, escalas e demais questões do instrumento.

Como resultado da análise dos juízes, três itens referentes a conhecimentos e cinco sobre atitudes foram excluídos por serem repetitivos. Alguns itens tiveram a redação aprimorada para facilitar a compreensão e foram feitos pequenos ajustes nas instruções, a fim de torná-las mais claras e objetivas.

\section{Composição Final do Instrumento}

Após todos os levantamentos realizados, a análise semântica, a avaliação de especialistas e uma última análise feita pelo grupo de pesquisa, a versão final do instrumento ficou composta por 86 itens, sendo 25 itens referentes a conhecimentos, 26 itens sobre habilidades e 35 itens retratando atitudes esperadas dos profissionais da Organização.

O questionário continha ainda uma página inicial com instruções: objetivo, solicitação de resposta individual, destaque para a confidencialidade das respostas e agradecimento pela colaboração. Havia também três questões abertas, para que o respondente pudesse acrescentar conhecimentos, habilidades e atitudes consideradas por ele relevantes e que não faziam parte do instrumento. Na sua parte final, foram incluídas questões sobre características pessoais e profissionais, a fim de caracterizar os participantes da pesquisa, e um espaço destinado a qualquer tipo de comentário que o respondente desejasse fazer.

Para todos os itens do questionário havia dois tipos de respostas: um sobre o grau de importância, que variava de 1 a 5 (de sem importância à extremamente importante), e outro sobre a percepção do grau de conhecimento, domínio ou desenvolvimento que o respondente possuía em relação à competência expressa no item. Desse modo, nos itens referentes a conhecimentos, o participante optava entre os graus de conhecimento de 1 a 5 (não tenho conhecimento a conheço totalmente); nas habilidades, respondia de acordo com graus de domínio, que 
variavam de 1 a 5 (de não domino a domino totalmente); e, por último, no tocante às atitudes, a escala representava graus de desenvolvimento de 1 a 5 (de não tenho desenvolvida a tenho totalmente desenvolvida).

\section{Procedimentos de Coleta de Dados}

A fim de garantir o maior número de participantes, optou-se por aplicar coletivamente o questionário no auditório da Organização, em dois turnos, explicando-se inicialmente aos respondentes o objetivo da pesquisa, o processo de desenvolvimento do instrumento e a importância de sua colaboração. Os dados foram coletados por meio de cooperação voluntária dos respondentes, respeitandose o seu direito de privatividade e garantindo-lhes que as informações prestadas não seriam utilizadas para outra finalidade, que não a da pesquisa.

\section{Resultados}

A seguir, encontram-se descritas as características da amostra e apresentados os principais resultados obtidos a partir da aplicação do referido questionário.

\section{Caracterização da Amostra}

A amostra foi composta por 66 servidores, o que correspondia a 68,7\% do total de profissionais da Organização. A não participação de 31,3\% dos servidores na pesquisa deveu-se a ausências por motivo de férias, abono ou serviço externo.

A maioria dos respondentes é do sexo feminino (80,3\%), sendo apenas 19,7\% do sexo masculino. A maior parte dos sujeitos encontrava-se na faixa etária de 36 a 40 anos e tinha como nível de escolaridade o curso superior completo (47\%). O tempo médio de trabalho na área de recursos humanos era de cerca de 10 anos, sendo que um total de $52 \%$ dos respondentes tinha menos de 11 anos de experiência em recursos humanos. Os participantes da pesquisa eram de diferentes diretorias da Organização.

\section{Níveis de Importância e de Detenção dos Conhecimentos, Habilidades e Atitudes}

Devido ao grande número de itens do instrumento, optou-se por descrever no presente artigo apenas os conhecimentos, habilidades e atitudes considerados mais importantes (cinco itens em cada categoria), bem como os componentes de 
competências que os participantes afirmavam que mais e que menos possuíam na ocasião da pesquisa e suas respectivas médias.

\section{Conhecimentos}

Os cinco itens referentes a conhecimentos considerados mais importantes pelos participantes da pesquisa foram (maior média igual a 4,65 e menor média igual a 4,26):

. Ter conhecimento sobre regimento interno da Organização - 4,65

. Conhecer a missão e os objetivos da Unidade Principal - 4,47

- Conhecer os recursos disponíveis nos equipamentos (telefone, computador, datashow, retroprojetor etc.) $-4,45$

- Conhecer as características essenciais do grupo a que se destina o evento 4,30

- Ter noções básicas sobre motivação no trabalho - 4,26

Os itens referentes aos conhecimentos que os servidores afirmaram possuir mais foram (maior média igual a 3,00):

- Ter conhecimento sobre regimento interno da Organização - 3,00

- Conhecer os recursos disponíveis nos equipamentos no trabalho (telefone, computador, datashow, retroprojetor etc.) e Conhecer fatores que interferem na aplicação dos conhecimentos adquiridos no treinamento no local de trabalho $-2,88$

- Ter noções básicas sobre motivação no trabalho - 2,83

- Conhecer a tramitação de procedimentos administrativos - 2,80

. Conhecer a missão e os objetivos da Secretaria - 2,77

Os cinco itens referentes aos conhecimentos que os servidores afirmaram possuir menos (menor média igual a 1,97):

- Ter noções sobre consultoria interna $-1,97$

- Ter noções básicas de pesquisa aplicada - 2,00

- Ter noções de estatística (tabelas, gráficos etc.) - 2,09 
. Ter noções básicas sobre educação a distância - 2,12

. Ter conhecimentos sobre modelos de gestão de desempenho - 2,14

\section{Habilidades}

Os itens referentes a habilidades considerados mais importantes pelos participantes da pesquisa foram (maior média 4,82 e menor média igual a 4,70):

. Ser capaz de trabalhar em equipe $-4,82$

. Redigir sem erros de português - 4,80

- Ser capaz de organizar seu trabalho de modo que outra pessoa possa dar continuidade e Comunicar-se por escrito com clareza - 4,77

. Saber elaborar relatórios e projetos $-4,70$

- Saber transmitir com clareza aos treinandos as características essenciais dos eventos da Organização - 4,68

Os cinco itens referentes às habilidades que os servidores afirmaram dominar mais foram (maior média igual a 3,97):

- Ser capaz de organizar seu trabalho de modo que outra pessoa possa dar continuidade $-3,97$

. Ser capaz de trabalhar em equipe - 3,89

. Ser capaz de adaptar-se a situações novas - 3,68

- Ser capaz de orientar os prestadores de serviços de forma clara e objetiva 3,50

. Redigir sem erros de português - 3,33

Os cinco itens referentes às habilidades que os servidores afirmaram dominar menos foram (menor média igual a 1,47):

. Saber usar o programa Access - 1,47

. Saber usar o programa Excel - 1,58

. Saber usar o programa PowerPoint - 1,59

- Saber fazer mala direta - 1,65 
- Saber redigir portarias, leis, decretos, ordens de serviço - 2,11

\section{Atitudes}

Os itens referentes às atitudes consideradas mais importantes pelos participantes da pesquisa foram (maior média 4,91 e menor média igual a 4,79, sendo que as quatro últimas atitudes listadas a seguir obtiveram o mesmo escore de importância):

- Agir com ética na relação com pessoas no trabalho - 4,91

- Primar pela qualidade de seu trabalho $-4,88$

- Assumir responsabilidades nas atividades que lhe são destinadas - 4,85

- Ser atencioso com os colegas de trabalho e Atender de forma cordial os participantes dos eventos e prestadores de serviços e Adotar postura adequada para representar a Organização - 4,80

- Estar comprometido com os interesses da Organização - 4,79

Os cinco itens referentes às atitudes que os servidores afirmaram ter mais desenvolvidas foram (maior média igual a 4,50):

- Assumir responsabilidades nas atividades que lhes são destinadas - 4,50

- Agir com ética na relação com pessoas no trabalho - 4,45

. Preservar o patrimônio da Organização - 4,44

- Primar pela qualidade de seu trabalho - 4,39

- Contribuir para um clima favorável de trabalho - 4,29

Os cinco itens referentes às atitudes que os servidores afirmaram ter menos desenvolvidas foram (menor média igual a 2,60):

- Articular-se com outras instituições para estabelecimento de parcerias ou convênios - 2,60

- Manter-se atualizado em leituras sobre a área de Gestão de Pessoas - 2,70

- Buscar diferentes meios para divulgar os eventos promovidos pela Organização $-3,03$ 
- Ter iniciativa para solicitar reuniões para discussão dos problemas do dia-a-dia $-3,06$

- Manter-se atualizado sobre os projetos desenvolvidos na Organização - 3,29

Para melhor compreensão dos resultados obtidos com a aplicação do referido questionário, apresentam-se a seguir duas tabelas, sendo a primeira com as maiores médias e a segunda com as menores médias de importância e de grau de detenção das competências, na percepção dos servidores da Organização.

Tabela 1: Maiores Médias de Importância e do Grau que os Servidores Afirmam Deter os Componentes de Competências

\begin{tabular}{l|c|c}
\hline \multicolumn{1}{c|}{ FATORES } & $\begin{array}{c}\text { MAIOR GRAU } \\
\text { DE } \\
\text { IMPORTÂNCIA }\end{array}$ & $\begin{array}{c}\text { MAIOR GRAU DE POSSE, } \\
\text { DOMÍNIO OU } \\
\text { DESENVOLVIMENTO }\end{array}$ \\
\hline CONHECIMENTOS & 4,65 & 3,00 \\
\hline HABILIDADES & 4,82 & 3,97 \\
\hline ATITUDES & 4,91 & 4,50 \\
\hline
\end{tabular}

Tabela 2: Menores Médias de Importância e do Grau que os Servidores Afirmam Deter os Componentes de Competências

\begin{tabular}{l|c|c}
\hline \multicolumn{1}{c|}{ FATORES } & $\begin{array}{c}\text { MENOR GRAU } \\
\text { DE } \\
\text { IMPORTÂNCIA }\end{array}$ & $\begin{array}{c}\text { MENOR GRAU DE POSSE, } \\
\text { DOMÍNIO OU } \\
\text { DESENVOLVIMENTO }\end{array}$ \\
\hline CONHECIMENTOS & 3,32 & 1,97 \\
\hline HABILIDADES & 3,95 & 1,47 \\
\hline ATITUDES & 4,15 & 2,60 \\
\hline
\end{tabular}

Na Tabela 3, a seguir, pode-se comparar as médias gerais de conhecimentos, habilidades e atitudes, a fim de se observar os graus de importância e de posse atribuídos pelos participantes da pesquisa. 
Tabela 3: Médias Gerais de Importância e do Grau que os Servidores Afirmam Possuir os Componentes de Competências

\begin{tabular}{l|c|c}
\hline \multicolumn{1}{c|}{ FATORES } & $\begin{array}{c}\text { MÉDIA DOS } \\
\text { GRAUS DE } \\
\text { IMPORTÂNCIA }\end{array}$ & $\begin{array}{c}\text { MÉdIA DOS GRAUS DE POSSE, } \\
\text { DOMÍNIO OU } \\
\text { DESENVOLVIMENTO }\end{array}$ \\
\hline CONHECIMENTOS & 4,02 & 2,46 \\
\hline HABILIDADES & 4,43 & 2,78 \\
\hline ATITUDES & 4,66 & 3,82 \\
\hline
\end{tabular}

\section{Correlação entre a Importância das Competências e os Dados Pessoais dos Servidores}

Foram calculadas correlações de Pearson entre as médias dos componentes de competências (conhecimentos, habilidades e atitudes) e as características pessoais e profissionais dos participantes da pesquisa. Na Tabela 4, a seguir, são apresentadas correlações significativas $(\mathrm{p} \leq 0,05)$ e assinaladas as que não se mostraram significativas (n.s.).

Tabela 4: Correlações entre as Competências e Variáveis Pessoais e Profissionais dos Respondentes

\begin{tabular}{|c|c|c|c|c|}
\hline FATORES & SEXo (GÊNERO) & FAIXA EtáRIA & ESCOLARIDADE & CARGo OU FUnÇão \\
\hline $\begin{array}{l}\text { CONHECIMENTOS } \\
\text { Grau de Detenção }\end{array}$ & n.s. & $\begin{array}{l}r=0,31 \\
p=0,01\end{array}$ & $\begin{array}{c}r=0,63 \\
p \leq 0,0001\end{array}$ & $\begin{array}{l}r=-0,25 \\
p=0,05\end{array}$ \\
\hline $\begin{array}{l}\text { CONHECIMENTOS } \\
\text { Grau de Importância }\end{array}$ & n.s. & n.s. & n.s. & $\begin{array}{l}r=-0,29 \\
p=0,02\end{array}$ \\
\hline $\begin{array}{c}\text { HABILIDADES } \\
\text { Grau de Importância }\end{array}$ & n.s. & n.s. & n.s. & n.s. \\
\hline $\begin{array}{l}\text { HABILIDADES } \\
\text { Grau de Domínio }\end{array}$ & n.s. & n.s. & $\begin{array}{c}r=0,53 \\
p \leq 0,0001\end{array}$ & n.s. \\
\hline $\begin{array}{c}\text { ATITUDES } \\
\text { Grau de Importância }\end{array}$ & $\begin{array}{c}r=-0,25 \\
p=0,05\end{array}$ & n.s. & n.s. & n.s. \\
\hline $\begin{array}{c}\text { ATITUDES } \\
\text { Grau de } \\
\text { Desenvolvimento }\end{array}$ & n.s. & $\begin{array}{l}r=0,25 \\
p=0,05\end{array}$ & $\begin{array}{c}r=0,44 \\
p \leq 0,0001\end{array}$ & n.s. \\
\hline
\end{tabular}




\section{Sexo (Gênero)}

Tendo em vista que a correlação entre a variável sexo e a média das respostas do Grau de Importância das Atitudes foi negativa $(r=-0,25 ; p=0,05)$, fica evidenciado que os homens tenderam a atribuir menor importância às atitudes do que as mulheres. É possível que as diferenças de gênero no trabalho, que geralmente exigem da mulher maior competência para vencer as barreiras à sua ascensão profissional, conforme comenta Rubery (1995), tenham contribuído para esse resultado.

\section{Faixa Etária}

A correlação positiva entre a média do Grau de Detenção do Conhecimento e a variável faixa etária $(r=0,31 ; \mathrm{p}=0,01)$ indica que os servidores com mais idade consideraram que possuem mais conhecimento do que aqueles de menor idade. Relação semelhante pode ser vista no que se refere ao Grau de Desenvolvimento de Atitudes, pois a correlação positiva $(r=0,25 ; p=0,05)$ indica que as pessoas com maior faixa etária afirmaram possuir as atitudes mais desenvolvidas do que os de menor faixa etária. Esse resultado parece natural, uma vez que se pressupõe que as pessoas de maior idade tenham tido mais oportunidades de aprendizagem e aquisição de experiências ao longo de suas vidas.

\section{Grau de Escolaridade}

No tocante à variável grau de escolaridade, observa-se que a correlação foi altamente significativa ( $\mathrm{r}=0,63 ; \mathrm{p}=0,0001)$, demonstrando que quanto maior $\mathrm{o}$ grau de escolaridade maior a percepção de que os servidores possuem os conhecimentos relacionados no questionário. O mesmo foi notado com relação ao domínio de habilidades, porque, com base nos valores da correlação ( $\mathrm{r}=0,53$; $\mathrm{p}=0,0001$ ), foi possível verificar que quanto maior o grau de escolaridade, maior a percepção de que se tem domínio de habilidades. No que se refere às atitudes, percebeu-se, a partir dos valores da correlação $(r=0,44 ; p=0,0001)$, que quanto maior o grau de escolaridade, maior a percepção dos servidores de que desenvolveram mais tais atitudes. Esses resultados podem evidenciar que as pessoas de maior escolaridade tenham provavelmente sido expostas a maior número de situações de aprendizagem que lhe permitiram adquirir conhecimentos, habilidades e atitudes.

\section{Cargo ou Função}

A correlação negativa ( $r=-0,25 ; p=0,05)$ entre a média do Grau de Detenção do Conhecimento e a variável cargo ou função indica que os profissionais que 
exerciam funções ou cargos de assessor, gerente de equipe e diretor tenderam a perceber que possuem mais conhecimento do que os das demais funções. Uma vez que a correlação da variável cargo ou função com o Grau de Importância dos Conhecimentos também foi negativa ( $r=-0,29$; $p=0,02)$, chega-se a conclusão semelhante, ou seja, a de que esses profissionais atribuíram maior importância aos conhecimentos do que aqueles que exercem outras funções.

\section{Respostas às Questões Abertas}

As respostas às perguntas abertas, que questionavam a existência de outros conhecimentos, habilidades e atitudes importantes para as funções dos servidores da Organização, retrataram aspectos referentes à melhoria da comunicação entre os níveis hierárquicos, à melhoria do relacionamento interpessoal, ao papel do Estado e da sociedade, a mudanças no governo e à disponibilidade de materiais, entre outros. Algumas respostas apenas reforçavam a importância de conhecimentos, habilidades e atitudes constantes dos itens do questionário.

\section{Discussão e Conclusões}

O presente estudo teve como objetivo principal construir e aplicar um instrumento destinado a identificar lacunas de competências de profissionais de T\&D de uma organização pública. Embora não tenha sido possível validar estatisticamente o questionário, em razão do número de servidores da referida organização ser insuficiente para realizar tal procedimento, os resultados são indicativos dos conhecimentos, habilidades e atitudes necessários ao bom desempenho desses servidores, bem como da existência, na percepção dos próprios servidores, de lacunas de competências profissionais.

Pode-se notar que as médias de importância dos itens relativos a conhecimentos ficaram entre 3,32 (medianamente importante com tendência a muito importante) e 4,65 (muito importante com tendência a extremamente importante), enquanto as médias de detenção de conhecimento, por parte dos servidores, ficaram entre 1,97 (conheço pouco) e 3,00 (conheço medianamente).

Tais resultados levam à conclusão de que os participantes da pesquisa, embora avaliem quase todos os itens referentes a conhecimentos como importantes para o desempenho de suas funções, consideram que possuem pouco conhecimento sobre tais aspectos. Ressalta-se, ainda, que os servidores afirmaram conhecer pouco sobre consultoria interna, educação a distância e gestão de desempenho, temas emergentes na área de Gestão de Pessoas. 
No tocante às habilidades, comparando-se graus de importância com graus de domínio, percebe-se que não há discrepância marcante entre as habilidades consideradas mais importantes e aquelas que os servidores afirmaram possuir mais. É possível observar, no entanto, que as médias de importância dos itens ficaram entre 3,95 (muito importante) e 4,82 (muito importante com tendência a extremamente importante), enquanto as médias dos graus de domínio das habilidades, por parte dos servidores, ficaram entre 1,47 (não domino com tendência a domino pouco) e 3,97 (domino muito). Tais observações levam à conclusão de que os participantes da pesquisa, embora indiquem quase todos os itens referentes às habilidades como muito ou extremamente importantes para o desempenho de suas funções, consideram que dominam medianamente ou pouco tais habilidades.

De forma geral, as atitudes foram consideradas pelos servidores como mais importantes que os conhecimentos e habilidades descritos no questionário. Merece atenção especial, no entanto, a predisposição de “articular-se com outras instituições para estabelecimento de parcerias ou convênios”, uma das atitudes consideradas menos desenvolvidas pelos respondentes. Tal resultado evidencia a provável falta de articulação da instituição pública com outras organizações.

Ressalta-se, ainda, que os servidores alegam também possuir atitudes em maior grau de desenvolvimento que conhecimentos e habilidades. Isto porque o domínio de conhecimentos e habilidades foi considerado pouco ou mediano, enquanto as atitudes foram percebidas como medianamente ou muito desenvolvidas.

Destaca-se que o objetivo do estudo pôde ser concretizado, pois a aplicação do referido instrumento permitiu identificar aspectos que necessitam investimentos em ações de T\&D. No entanto deve-se atentar prioritariamente para os aspectos que apresentaram grande índice de importância e pequena média de detenção, domínio ou desenvolvimento. Seria recomendável a realização de uma análise comparativa entre as respostas dos sujeitos ao instrumento (auto-avaliação) com avaliação das diretorias, com base nas competências profissionais desejadas em cada área, tendo por base as estratégias da Organização.

Outras análises podem ser feitas, considerando, por exemplo, o cruzamento de dados pessoais e profissionais com o domínio de conhecimentos, habilidades e atitudes. Em futuras aplicações do instrumento, entretanto, recomenda-se avaliar a necessidade de atualizar os componentes de competências profissionais ali descritos, sobretudo em razão de mudanças na estratégia da Organização ou no papel ocupacional desempenhado por seus servidores. 


\title{
Nota
}

\begin{abstract}
${ }^{1}$ Para Prahalad e Hamel (1990), competências organizacionais - core competences - referem-se a atributos organizacionais que atendem a três requisitos: gerar benefícios percebidos pelos clientes, ser difícil de imitar pela concorrência e prover acesso a diferentes mercados. Tais critérios, no entanto, aplicam-se apenas ao meio empresarial. Como a organização objeto deste estudo é pública e, portanto, não concorre em mercado específico, não foram considerados esses critérios, definindose competência organizacional, para efeito deste estudo, como atributo subjacente à organização, que lhe permite atingir seus objetivos estratégicos.
\end{abstract}

\section{Referências Bibliográficas}

BOYATZIS, R.

The competent manager: a model for effective performance. New York: John Wiley \& Sons, 1982.

BRANDÃO, H. P.

\section{Gestão baseada nas} competências: um estudo sobre competências profissionais na indústria bancária. Brasília, 1999. Dissertação (Mestrado em Administração) - Departamento de Administração, Universidade de Brasília.

BRANDÃO, H. P.;

GUIMARÃES, T. de A.

Gestão de competências e gestão de desempenho: tecnologias distintas ou instrumentos de um mesmo constructo? Revista de Administração de Empresas, v. 41, n. 1, p. 8-15, jan./mar. 2001.
BRANDÃO, H. P.;

GUIMARÃES, T. de A.;

BORGES-ANDRADE, J. E.

Professional competencies to achieve top standards of quality in retail banking services. In: THE BUSINESS ASSOCIATION OF LATIN AMERICA STUDIES BALAS CONFERENCE, 2001, San Diego. Proceedings... San Diego: BALAS, 2001.

BRUNO-FARIA, M. de F.; BRANDÃO, H. P.

Gestão de competências: identificação de competências relevantes a profissionais de $T \& D$ de uma organização pública do Distrito Federal. In: ENCONTRO ANUAL DA ANPAD, 26., 2002, Salvador. Anais... Salvador: ANPAD, 2002. 1 CD-ROM. 
DURAND, $\mathrm{T}$.

Forms of incompetence. In: FOURTH INTERNATIONAL CONFERENCE $\mathrm{ON}$ C O M P E T E N C E - B A S E D MANAGEMENT, 1998, Oslo. Proceedings... Oslo: Norwegian School of Management, 1998.

L’alchimie de la compétence. Revue Française de Gestion, v. 127, p. 84-102, jan./fév. 2000.

DUTRA, J. S.;

HIPÓLITO, J. A. M.;

SILVA, C. M.

Gestão de pessoas por competências: o caso de uma empresa do setor de telecomunicações. In: ENCONTRO ANUAL DA ANPAD, 22., 1998, Foz do Iguaçu. Anais... Foz do Iguaçu: ANPAD, 1998. 1 CD-ROM.

FLEURY, A.;

FLEURY, M. T. L.

Estratégias empresariais e formação de competências: um quebra-cabeça caleidoscópico da indústria brasileira. São Paulo: Atlas, 2001.

GUIMARÃES, T. de A. et al.

Forecasting core competencies in R\&D environment. $\quad \mathbf{R} \& \mathbf{D}$ Management Review, v. 31, n. 3, p. 249-255, July 2001.

IENAGA, C. H.

Competence based mana- gement: seminário executivo. São Paulo: Dextron Consultoria Empresarial, 1998.

ISAMBERT-JAMATI, V.

$\mathrm{O}$ apelo à noção de competência na revista L'orientation Scolaire et Profissionelle: da sua criação aos dias de hoje. In: ROPÉ, F.; TANGUY, L. (Orgs.). Saberes e competências: o uso de tais noções na escola e na empresa. Campinas: Papirus, 1997.

LE BOTERF, G.

Competénce et navigation professionnelle. Paris: Éditions D’Organisation, 1999.

MAGALHÃES, M. L.

Auto e hetero avaliação no diagnóstico de necessidades de treinamento. Brasília, 1996. Dissertação (Mestrado em Psicologia Social e do Trabalho) Instituto de Psicologia, Universidade de Brasília.

MCLAGAN, P.

Competencies: the next generation. Training \& Development, p. 4047, May 1997.

NISEMBAUM, H.

A competência essencial. São Paulo: Infinito, 2000.

PASQUALI, L.

Análise dos itens. In:

Psicometria: teoria e aplicações. Brasília: Universidade de Brasília, 1997. 
PRAHALAD, C. K.;

HAMEL, G.

The core competence of the corporation. Harvard Business Review, p. 79-91, May/June 1990.

ROPÉ, F.;

TANGUY, L.

Introdução. In: (Orgs.).

Saberes e competências: o uso de tais noções na escola e na empresa. Campinas: Papirus, 1997.

\section{RUAS, R.}

Mestrado executivo, formação gerencial e a noção de competências: provações e desafios. In: ENCONTRO ANUAL DA ANPAD, 25., 2001, Campinas. Anais... Campinas: ANPAD, 2001. 1 CD-ROM.

RUBERY, J.

Performance-related pay and prospects for gender pay equity. Journal of Management Studies, v. 32, n. 5, p. 637-654, Sept. 1995.

SANTOS, A. C.

O uso do método Delphi na criação de um modelo de competências.
Revista de Administração, v. 36, n. 2, p. 25-32, abr./jun. 2001.

SOUZA, E. C. L. de.

Gestão de organizações de aprendizagem. Brasília: UnBSESI, 2001.

SPENCER, L.; SPENCER, S.

Competence at work: models for superior performance. New York: John Wiley \& Sons, 1993.

STEWART, T.

Capital intelectual: a nova vantagem competitiva das empresas. Rio de Janeiro: Campus, 1998.

\section{ZARIFIAN, P.}

A gestão da e pela competência. Rio de Janeiro, Seminário Educação Profissional, Trabalho e Competências, Centro Internacional para a Educação, Trabalho e Transferência de Tecnologia, 1996. mimeo.

Objectif compétence: pour une nouvelle logique. Paris: Liaisons, 1999. 